\section{PERCEPÇÃO AMBIENTAL E MOTIVAÇÃO EM EDUCAÇÃO AMBIENTAL PARA ADOLESCENTES: CONCEITOS BÁSICOS E PROPOSTA DE PESQUISA}

Marciana Catanho ${ }^{1}$

Roberto Teixeira de Lima²

CATANHO, M.; LIMA, R. T. de. Percepção ambiental e motivação em educação ambiental para adolescentes: conceitos básicos e proposta de pesquisa. EDUCERE - Revista da Educação, Umuarama, v. 21, n. 2, p. 227-251, jul./dez. 2021.

RESUMO: O presente artigo tem por objetivos trazer à reflexão a importância dos estudos a respeito da percepção ambiental e da motivação dos atores sociais como fontes de informação para subsidiar a preparação do arcabouço teórico e prático em que se deve fundamentar a instrumentação para ações em educação ambiental, e, ao final, apresentar uma síntese de uma proposta de pesquisa relacionando percepção ambiental, motivação e educação ambiental tendo os adolescentes como atores sociais. Para tanto, inicialmente, mostra-se importante trazer, como conteúdo básico para discussão, algumas definições específicas que possibilitam compreender como os conceitos fundamentais expostos se inter-relacionam na construção da proposta de trabalho apresentada.

PALAVRAS-CHAVE: Percepção ambiental; Motivação; Educação ambiental; Adolescentes; Adolescência.

DOI: $10.25110 /$ educere.v21i2.2021.7965

${ }^{1}$ Secretaria de Educação do Estado de São Paulo. marci.catanho@gmail.com. https://orcid.org/0000-0002-4916$014 \mathrm{X}$

${ }^{2}$ Secretaria de Infraestrutura e Meio Ambiente do Estado de São Paulo. roberto.t.lima@gmail.com. https://orcid. org/0000-0001-7217-4876 


\section{ENVIRONMENTAL PERCEPTION AND MOTIVATION IN ENVIRONMENTAL EDUCATION FOR ADOLESCENTS: BASIC CONCEPTS AND RESEARCH PROPOSAL}

ABSTRACT: This paper has the purpose of reflecting on the importance of studies regarding the environmental perception and motivation of social players as sources of information to support the preparation of theoretical and practical content on which to base the instrumentation for actions in environmental education. At the end, it provides a summary of a research proposal relating environmental perception, motivation and environmental education to adolescents as social players. In order to do so, it must present specific definitions as basic content for discussion, to allow the understanding of how the fundamental concepts presented are interrelated with the construction of the research proposal presented.

KEYWORDS: Environmental perception; Motivation; Enviromental education; Adolescents; Adolescence.

\section{PERCEPCIÓN AMBIENTAL Y MOTIVACIÓN EN EDUCACIÓN AMBIENTAL PARA ADOLESCENTES: CONCEPTOS BÁSICOS Y PROPUESTA DE INVESTIGACIÓN}

RESUMEN: Este artículo tiene como objetivo traer a la reflexión la importancia de los estudios sobre la percepción ambiental y la motivación de los actores sociales como fuentes de información para apoyar la preparación del marco teórico y práctico en el que debe basarse la instrumentación para las acciones en educación. ambiental y, al final, presentar una síntesis de una propuesta de investigación que relaciona la percepción ambiental, motivación y la educación ambiental con los adolescentes como actores sociales. Para este fin, inicialmente, es importante traer, como contenido básico para la discusión, algunas definiciones específicas que permitan comprender cómo los conceptos fundamentales expuestos están interrelacionados en la construcción de la propuesta de trabajo presentada.

PALABRAS CLAVE: Percepción ambiental; Motivación; Educación ambiental; Adolescentes; Adolescencia. 


\section{INTRODUÇÃO}

O presente artigo tem como objetivo apresentar subsídios para a reflexão a respeito de uma perspectiva de incorporação e sinergia entre estudos em percepção ambiental e em motivação como arcabouço científico para a construção teórica e o desenvolvimento de um estudo participativo em educação ambiental. Para isso, são apresentadas bases teóricas e algumas experiências anteriores em percepção ambiental e em motivação, realizadas pelos próprios autores, que nortearão uma nova proposta de pesquisa integrada.

Tratando-se de problemas ambientais, a educação ambiental destaca-se como um conjunto de ideias, técnicas, práticas e ferramentas com potencial para alcançar objetivos em comum da sociedade e apresentar soluções.

Há décadas, ficaram reconhecidos que diversos fatores são determinantes para a eficiência e o alcance das ações em educação ambiental estabelecidas. Entre esses, destaca-se o indivíduo participante - o ator - como parte fundamental para o sucesso da busca por e na execução de uma solução - a ação.

Nesse sentido, Tuan (1980) apresenta que com o estabelecimento de relações afetivas com o ambiente, cada indivíduo obtém informações que interferem nas formas de seu relacionamento com seu entorno, potencialmente promovendo mudanças de atitude a partir de um determinado grau de envolvimento.

Conhecer essas relações afetivas permite analisar melhor situações de conflitos que se apresentam entre a sociedade e o meio ambiente. Santos et al. (1996) apresentam que a investigação das relações humano-ambiente, da percepção ambiental dos agentes envolvidos nos problemas ambientais estudados, contribui para a utilização menos impactante do meio ambiente.

Del Rio (1999) destaca a importância das pesquisas que tenha como objetivo levantar e conhecer as percepções individuais que, apesar de subjetivas, apresentam recorrências comuns em relação a situações e lugares socialmente compartilhados. O autor destaca que conhecer os conflitos e buscar soluções por meio de estudos de percepção ambiental e cognição permite um melhor direcionamento das ações para alcançar resultados mais eficientes e de maior qualidade.

Conforme Jacobi (2002), não se pode avaliar a situação de degradação do meio ambiente num contexto urbano sem que se faça análise dos processos, dos atores e de suas formas de organização social, torna-se essencial entender que o componente social é indissociável do componente ambiental. 
Nesse sentido, Jacobi (2003) explica que para embasar as reflexões a respeito de problemas ambientais é necessário que a produção de conhecimento contemple as inter-relações entre sociedade e meio ambiente, incluindo o papel dos atores e das formas de organização social envolvidas nas situações estudadas, dando-se ênfase na questão da sustentabilidade socioambiental.

Assim, reconhecida a importância da compreensão das relações afetivas e da participação de atores sociais para o sucesso das práticas em educação ambiental, torna-se imprescindível conhecer a percepção ambiental dos indivíduos que farão parte dessas práticas obtendo-se informações relevantes para a escolha, ou para a construção, do instrumental do qual a educação ambiental se empossará para potencializar as ações planejadas.

Ou seja, para assegurar que as práticas em educação ambiental obtenham êxito é necessário conhecer o público participante para que, então, seja possível construir, facilitar e direcionar as ações planejadas para se alcançar o resultado esperado.

\section{ALGUNS CONCEITOS E ALGUMAS DEFINIÇÕES}

\section{Educação ambiental}

Sabendo-se que Educação é um conceito amplo e complexo, é comum buscar dividi-la em expressões derivadas, a fim de tornar o significado da parte mais restrito e objetivo, limitando "o que" ou "a quem" aquela parte específica da Educação trata.

Assim surgiram tantas expressões com conceitos derivados, tais como: educação física, educação especial, educação sexual, educação para jovens e adultos, educação ambiental, educação para a cidadania, educação para o futuro, entre outros tantos, que são repartições derivadas do conceito maior, como subconjuntos de um todo, com intersecções flutuantes entre si, pois as próprias definições apresentadas a cada nova partição originada vão se modificando ao longo do tempo, se modelando e remodelando, numa evolução linguística permanente, observadas na literatura em definições tão variadas tanto quanto as suas aplicações reais.

Para Morin (2004), que preferiu a expressão "educação para o futuro", a educação deve ser transdisciplinar e integral e precisa discutir, em sua essência, questões fundamentais para a superação de problemas a fim de desenvolver-se 
a compreensão e a consciência de que todas as pessoas são partes da sociedade, partes do gênero humano e, assim sendo, são todos responsáveis pelo presente e pelo futuro da humanidade e, por meio da educação, superando as dificuldades existentes, é que a humanidade alcançará a cidadania em seu sentido mais amplo.

Muitas vezes, pela praticidade ou pelo seu reconhecimento instantâneo, expressões variadas, como educação para a cidadania e educação para o futuro, serão tratadas, comprimidas simplesmente como educação ambiental, como uma definição revista e ampliada, reconhecendo que desde sua apresentação formal, foi esse o conceito que acabou sendo a expressão consagrada tanto para a academia como para os legisladores.

Nesse sentido, a opção por usar uma expressão ou outra é uma questão que deve considerar não apenas o referencial teórico, os objetivos e os aspectos sociais e ambientais estudados, mas também os sujeitos envolvidos.

Em Lima (2008) optou-se pelo emprego da expressão "educação para cidadania" porque refletia melhor os objetivos daquele trabalho científico. Afinal, a educação perpassando a cidadania, em sinergia, deve possibilitar e incentivar a participação dos atores sociais nas discussões, na tomada de decisões, e nas ações, imediatas e futuras, visando o bem coletivo para o desenvolvimento e fortalecimento das relações humanas dentro da sociedade na qual estão inseridos e da qual são parte.

Para Reigota (2006), há uma grande variedade de práticas que se autodefiniam como educação ambiental e que, como perspectiva educativa, poderiam permear todas as disciplinas ao analisarem temas que permitam enfocar as relações entre a humanidade e o meio natural ao tratar as relações sociais existentes, desde que respeitando suas especificidades.

De qualquer modo, seja qual for à expressão conceitual empregada, para se realizar a educação ambiental, fundamentalmente, deve-se haver a compreensão geral do que é meio ambiente, mesmo sabendo-se que esse conceito será apresentado de forma variada de acordo com os interesses específicos de cada grupo social (p.ex., cientistas, artistas, políticos, filósofos, religiosos, etc.) (REIGOTA, 2001, 2006). 


\section{Percepção ambiental e cognição}

Segundo Tuan (1980), há três importantes princípios correlacionados que explicam como ocorre o estabelecimento de uma ideia como um conceito. Primeiramente, cada indivíduo é um ser biológico, participante de uma sociedade, ao mesmo tempo em que é único, e, daí, suas percepções, atitudes e valores refletem seu entendimento dos fatos percebidos. Em segundo lugar, grupos sociais podem expressar, e até impor, diferentes padrões culturais aos seus membros e aos outros grupos com os quais se relacionem. Por último, diante da enormidade de variações de experiências individuais, em qualidade e intensidade, e suas diferentes influências sobre a formação e a construção do ser humano, individual e socialmente, é necessário reconhecer as dificuldades em avaliar e mensurar tais experiências e suas manifestações.

A partir desses pensamentos, experiências e emoções, permitidos somente pela existência da percepção e da cognição, acontecem relações topofílicas e topofóbicas entre cada pessoa e o ambiente onde vivem e vivenciam suas novas experiências (TUAN, 1980).

Para Forgus (1981), a percepção está intimamente relacionada com a cognição, não podendo ser dissociadas uma da outra, acontecendo por meio do contínuo processo perceptivo (ou perceptivo-cognitivo) e pode ser explicado dentro do contexto da necessidade que o ser humano tem de se adaptar e se acomodar ao seu ambiente para enfrentar mais eficientemente as exigências da vida. A percepção é inseparável da cognição, formando uma estrutura mental superior contendo um conjunto de etapas incluindo processos de recepção, aquisição, assimilação e acomodação de informações, pensamento, e geração e utilização de conhecimento, durante os quais ocorre a aprendizagem.

Assim, a percepção ambiental é, ao mesmo tempo, a resposta dos sentidos ao ambiente (percepção sensorial) e, também, a atividade mental resultante dessa relação (percepção cognitiva) e possibilitam à pessoa conhecer e compreender seu entorno, permitindo criar, estabelecer ou modificar suas relações e inter-relações com o ambiente e com o mundo em que vive. Quando acontece a percepção e a cognição, surge um julgamento e uma atribuição de valores individuais. Portanto, percepção e cognição são sempre acompanhadas da atribuição de significados (TUAN, 1980).

Então, simplificadamente, a percepção é o processo com o qual um 
indivíduo recebe ou extrai certas informações do ambiente e a aprendizagem é o processo pelo qual uma informação adquirida através da experiência se torna parte do armazenamento de fatos. Ocorrendo a aprendizagem há a facilitação de nova extração de informação, uma vez que os fatos armazenados se tornam modelos de acordo com os quais são julgadas as novas informações recebidas pelo processo perceptivo. Embora comumente sejam diferenciados por definições próprias, a percepção, o pensamento e a aprendizagem são três processos cognitivos intimamente relacionados sendo difícil separá-los na prática (FORGUS, 1981).

Corroborando com a ideia de indissociabilidade do processo perceptivocognitivo, Oliveira (1977), embasada no conhecimento a respeito das teorias piagetianas, afirma que a percepção não pode ser estudada de forma isolada, assim como não pode ser isolada do cotidiano das pessoas e deve ser compreendida como um elenco de fases da ação do sujeito sobre os objetos perceptíveis, num processo psicológico encadeado, interligado e interdependente de etapas que vão muito além de apenas experienciar um objeto.

Conforme a mesma autora, é necessário que o sujeito disponha de um sofisticado e complexo sistema para receber os dados sensoriais para, posteriormente, transformá-los em dados perceptivos, para que, então, ocorra a percepção e cognição, e é nos estudos desenvolvidos e publicados por Jean Piaget que melhor se discute o fenômeno da percepção do ponto de vista psicológico, por meio de uma explicação cognitiva na qual a percepção é vista como parte integrante da vida do indivíduo e entendida como atividade que desempenha papel fundamental na aprendizagem e na construção do pensamento lógico.

Portanto, a percepção e a cognição levam ao aprendizado, através dos sentidos e do processo cognitivo quando as informações percebidas são processadas, selecionadas e armazenadas de acordo com o interesse e a necessidade, recebendo, então, um significado para o indivíduo (DEL RIO; OLIVEIRA, 1999).

\section{Motivação e emoção}

Da mesma maneira que educação ambiental e percepção ambiental, motivação é outro conceito que apresenta diferentes definições na literatura, que variam de acordo com o campo científico que faz sua aplicação e de acordo com qual das diferentes teorias motivacionais está sendo fundamentado.

Segundo Reeve (2019), o conceito motivação envolve variados temas, 
suposições, hipóteses, teorias, constatações e domínios de aplicação, tendo surgido há muito tempo, com os filósofos gregos da antiguidade Sócrates, Platão e Aristóteles.

Conforme Bergamini (1986), para melhor organizar e compreender os aspectos das teorias motivacionais é imprescindível fazer um levantamento histórico dos estudos a respeito da motivação. Em Catanho (2018) estão apresentadas uma perspectiva histórica a respeito do conceito de motivação e também, sinteticamente, algumas das teorias motivacionais interessantes ao presente trabalho.

De acordo com Reeve (2019), estudar a motivação requer compreender os processos que energizam e direcionam o comportamento e o uso do termo "processo" ocorre porque ainda não há consenso a respeito dos motivos. Necessidades, cognições, emoções e reações a eventos ambientais são diferentes formas de se interpretar a origem básica dos motivos e para compreender a motivação e a emoção é necessário ter a capacidade de prever os efeitos de diferentes condições interpessoais, intrapsíquicas, fisiológicas e ambientais influenciando e promovendo a emoção e a motivação.

Ainda, segundo o mesmo autor, cognições são modos de pensar e são eventos mentais. Emoções são fenômenos que organizam a maneira como os indivíduos reagem e se adaptam aos eventos vividos, podendo ser subjetivos, fisiológicos, funcionais, expressivos e de vida curta. Necessidades são quaisquer condições que ocorrem, sendo essenciais para a vida acontecer e para o indivíduo se desenvolver, e devem ser atendidas para manter o bem-estar pessoal. Assim, os motivos continuamente interligam-se com as emoções, as cognições e as necessidades.

Segundo Bzuneck (2009), a motivação pode ser entendida como um fator psicológico, um conjunto de fatores ou, ainda, um processo psicológico. A motivação leva a uma escolha, instiga ou faz iniciar um comportamento direcionado a um objetivo e assegura a persistência em continuar e enfrentar possíveis dificuldades, ou fracassos, que surjam no percurso e faz com que o indivíduo não interrompa o caminho, mude o curso ou desista da ação.

Daí, ser motivado implica em ser movido a fazer alguma coisa, a agir ou a promover uma ação, a partir de pensamentos, emoções e necessidades. Uma pessoa que não sente um impulso ou uma inspiração para agir é, assim, caracterizada como desmotivada. Ao contrário, alguém que está inspirado, ativado ou animado para 
uma ação é considerado motivado. Assim, conclui-se que há relação direta entre percepção, cognição, pensamento, emoção e motivação.

\section{Teoria da Autodeterminação (TAD)}

Conforme Reeve (2019), segundo a Teoria da Autodeterminação, a motivação encontra-se dividida em três tipos: motivação intrínseca, motivação extrínseca e falta de motivação. Além disso, esses tipos de motivação são classificados com regulações diversas que variam de intensidade, como apresentados na Tabela 1.

Tabela 1: Taxonomia de motivação (Reeve, 2019, p.97, modificada).

\begin{tabular}{|c|c|c|c|c|c|}
\hline Desmotivação & \multicolumn{4}{|c|}{ Motivação Extrínseca } & $\begin{array}{c}\text { Motivação } \\
\text { Intrínseca }\end{array}$ \\
\hline Não-regulação & $\begin{array}{c}\text { Regulação } \\
\text { Externa }\end{array}$ & $\begin{array}{c}\text { Regulação } \\
\text { Introjetada }\end{array}$ & $\begin{array}{c}\text { Regulação } \\
\text { Identificada }\end{array}$ & $\begin{array}{c}\text { Regulação } \\
\text { Integrada }\end{array}$ & $\begin{array}{c}\text { Regulação } \\
\text { Intrínseca }\end{array}$ \\
\hline
\end{tabular}

A qualidade da motivação está relacionada com o nível de internalização e depende de regulações externas, sendo que quanto maior o nível de autodeterminação do comportamento, melhor a qualidade motivacional.

Os tipos de motivação e suas regulações, basicamente, são:

\section{1) Desmotivação}

Na desmotivação ocorre uma ausência de impulso ou inspiração para agir. Ademais, a desmotivação é considerada não-regulada, pois não existe uma regulação nesse comportamento. Por isso, nessa categoria há desvalorização, sensação de incompetência, ausência de intensão e falta de controle. Por fim, a internalização da desmotivação é nula.

\section{2) Motivação extrínseca}

Existem reguladores nessa categoria que variam de acordo com a intensidade, dispostos num crescente indo da regulação externa, seguida por regulação introjetada, regulação identificada e chegando a regulação integrada, explicadas, resumidamente, a seguir:

a) Regulação externa

Quanto à regulação externa é fundamental destacar que esse tipo está ligado 
à recompensas ou punições externas. Os fatores externos controlam e regulam essa categoria, por exemplo, um prêmio, um castigo ou uma ordem. Observa-se que na regulação externa ocorre um fraco desempenho e os resultados obtidos são muito ruins. A internalização dessa regulação é extremamente fraca.

b) Regulação introjetada

A regulação introjetada é voltada para quando um indivíduo toma para si o motivo externo para realizar uma determinada atividade. Por exemplo, uma pessoa que faz determinada tarefa para não decepcionar outra pessoa. A internalização desse tipo de regulação é parcial.

c) Regulação identificada

É caracterizada por apresentar uma importância pessoal, uma valorização consciente. Nesse caso, o principal é a meta a ser alcançada. Por exemplo, um aluno que quer entrar em um curso superior acaba se empenhando nos estudos para isso. Nesse caso, o motivo é externo e o meio para se atingir esse objetivo é o instrumento. $\mathrm{O}$ indivíduo acaba se identificando com a relevância daquele comportamento e aceita a regulação como sendo própria.

d) Regulação integrada

Na regulação integrada existe uma concordância com o eu e uma consciência. Acontece quando a pessoa internaliza regras e/ou valores. É o tipo de motivação extrínseca de maior autodeterminação. Assim, quanto maior a autodeterminação, melhor o desempenho do indivíduo.

\section{3) Motivação intrínseca}

A motivação intrínseca é caracterizada pela alegria, ou satisfação inerente, em realizar uma atividade. Esse tipo de motivação encontra-se dentro da pessoa. A internalização da motivação intrínseca é a mais intensa de todas as três motivações e sua regulação é denominada intrínseca. 


\section{Adolescência e adolescentes}

Historicamente, a adolescência é um conceito relativamente recente tipicamente associado ao modo de vida e à estruturação social e familiar mais comun nas Américas, na Europa e nos países colonizados ou fortemente influenciados pelos modos de vida modernos e contemporâneos europeus, e é mais comumente associada a uma faixa etária estabelecida socialmente do que ao processo de desenvolvimento humano em si (BECKER, 1994).

Segundo Grossman (1998), durante a Idade Média foram feitos registros a respeito das etapas da vida que, influenciados pelo pensamento aristotélico, apresentavam as idades divididas em períodos definidos de sete anos: "enfant" que era a primeira idade e compreenderia do nascimento ao sétimo ano; "pueritia" seguindo dos sete aos catorze; "adolescere" que compreendia a próxima etapa que duraria até os 21, 28 anos, ou, dependendo da natureza de cada indivíduo, podendo se estender até aos 35 anos. Em seguida, as próximas etapas seriam "juventude" com a plenitude das atividades e das forças da pessoa e, por último, a "velhice" identificada quando os sentidos começariam a falhar.

Até meados do séc. XVII crianças e adolescentes recebiam tratamentos indistintos e o limite que separava a infância da vida adulta era a independência e a liberdade de suas ações. Somente com o surgimento das novas estruturas escolares que se estabeleceu, gradativamente, a relação entre idade e classe escolar, levando, consequentemente, a uma maior distinção entre crianças e adolescentes (BECKER, 1994).

Durante a idade média, também, não havia a consciência da particularidade da infância e não havia uma distinção entre crianças e adultos. A ideia de infância estava ligada à ideia de dependência e a sua saída, com o ingresso no mundo dos adultos, ocorria quando a criança tinha condições de viver sem a presença constante de sua mãe ou da pessoa responsável pelos seus cuidados. Quando um indivíduo ingressava na sociedade dos adultos não havia distinção entre eles. A indeterminação de uma idade específica para o fim da infância se estendia a outras atividades sociais, como jogos, profissões ou uso de armas (GROSSMAN, 1998).

Segundo Becker (1994), só mais recentemente, a partir da segunda metade do séc. XX, é que a adolescência passou a ter importância na configuração social, passando a ser foco da atenção de diversas instituições sociais, como escolas, igrejas e partidos políticos, e, ao mesmo tempo, dos meios de comunicação, que 
passaram a relacionar os adolescentes diretamente ao mercado consumidor. A partir dos anos 1960 se intensificou a prática de tentativa de manipulação da juventude por intermédio dos meios de comunicação, com a intenção de estabelecer e fortalecer padrões de consumo e de influência dentro das famílias, transformando os jovens em um gigantesco mercado de consumo para inúmeros produtos, alguns dos quais criados especialmente ou com sua publicidade voltada exclusivamente para os novos públicos específicos (crianças, adolescentes e jovens adultos). Desde então, simultaneamente, a adolescência vem se tornando cada vez mais longa e mais complexa em nossa sociedade.

Em relação à legislação, no Brasil, existe o Estatuto da Criança e do Adolescente (ECA), uma lei que, entre outras providências, traz uma definição de quem é criança e quem é adolescente. Nela, conforme Brasil (1990, Art. $2^{\circ}$ ), "considera-se criança, para os efeitos desta Lei, a pessoa até doze anos de idade incompletos, e adolescente, aquela entre doze e dezoito anos de idade". Em seguida, ainda, está apresentado, "Parágrafo único. Nos casos expressos em lei, aplica-se excepcionalmente esse Estatuto às pessoas entre dezoito e vinte e um anos de idade".

Ainda, segundo a mesma lei, crianças, adolescentes e um grupo específico de jovens entre 18 e 21 anos são considerados com direitos e deveres diferentes das demais pessoas e devem ser tratados de forma semelhante entre si, mas de forma diferente dos outros indivíduos da sociedade em geral, dada a "condição peculiar da criança e do adolescente como pessoas em desenvolvimento" (BRASIL, 1990, Art. $6^{\circ}$ ).

Para Becker (1994), os adolescentes são aqueles que estão vivendo a passagem contínua que separa a criança do adulto, cujas fases vão sendo desmontadas e superadas ao longo do tempo, enquanto vão, simultaneamente, refinando e ampliando o conhecimento do mundo vivido individualmente, em um processo natural de crescimento e de desenvolvimento humano. Ao longo da adolescência muitas das opiniões e atitudes reveladas na maturidade vão sendo manifestadas, desenvolvidas e consolidadas, na construção contínua do adulto. Segundo o mesmo autor, é importante que se reconheça, nos conflitos e nas atitudes do adolescente, uma rica fonte de força geradora de transformação, criativa e crescente, fundamental não só para o desenvolvimento do adolescente individualmente, mas, também, para a sociedade como um todo. 
Conforme Charbonneau (1980), o adolescente, antes de tudo, é uma pessoa que está em formação, que está deixando a infância e seguindo em direção ao mundo adulto e que, por meio de uma jornada que inevitavelmente mudará sua forma de sentir e compreender o mundo em que vive. A criança, durante um processo iniciado na infância, continuado e intensificado na adolescência, construirá para si seus valores, sentimentos e atitudes que estarão presentes no adulto, e a educação que receber ao longo do seu desenvolvimento influenciará sua integração na sociedade. Tal educação deve ser contínua, envolvendo família, escola e outros segmentos sociais que possam contribuir beneficamente para sua formação pessoal e social.

\section{ESTUDOS DE PERCEPÇÃO AMBIENTAL E DE MOTIVAÇÃO Percepção ambiental: uma experiência em Joanópolis (SP)}

Trata-se de uma experiência relatada por Lima (2008) que foi realizada em 2007 na cidade de Joanópolis, uma estância turística no interior de São Paulo, cujo município apresenta cerca de 12.000 habitantes, distante $125 \mathrm{~km}$ ao norte da capital estadual paulista, na divisa com Minas Gerais.

Resumidamente, o estudo teve como objetivo mostrar que os adolescentes de Joanópolis são importantes atores sociais que além de perceberem os problemas sociais e ambientais, também são capazes de propor soluções ou ações mitigadoras para resolvê-los ou, ao menos, minimizá-los, faltandolhes oportunidades para participarem de fóruns e debates para se manifestarem contribuindo diretamente nos processos decisórios participativos.

Partindo do pressuposto de que para propor ações para um coletivo é necessário ampliar a representação com uma amostragem para atender melhor aos objetivos comuns. Então, a análise e a síntese de dados obtidos de um grupo com um perfil em comum, mesmo que heterogêneo, podem se tornar uma fonte de informações valiosa para subsidiar ações coletivamente.

O público-alvo da pesquisa foi composto pelos estudantes do ensino médio da Escola Estadual “Cel. João Ernesto Figueiredo", única unidade escolar de ensino médio do município. Os adolescentes responderam a questionários desenvolvidos especificamente para a pesquisa, elaborados e empregando-se técnicas apropriadas para o levantamento da percepção ambiental.

Tratando de questões sociais e ambientais urbanas relevantes, 24 
problemas observados foram abordados em duas etapas com os adolescentes participantes, sendo $12 \mathrm{em}$ cada. A $1^{\mathrm{a}}$ etapa apresentou os problemas sociais: êxodo rural, desemprego, subemprego, loteamentos clandestinos ou irregulares, falta de iluminação pública, falta de asfaltamento e calçamento, deficiência de transporte público, trânsito, criminalidade e violência urbana, falta de áreas para recreação e de locais para prática de esportes, e falta de atividades de recreação e/ou artísticas e culturais. A $2^{\mathrm{a}}$ etapa apresentou os problemas ambientais: deficiência de áreas verdes e de arborização nas ruas, ausência de matas ciliares, erosão e assoreamento de rios e córregos, alagamentos e enchentes, poluição das águas, sistema deficiente de coleta e de tratamento de esgoto, falta de coleta seletiva de lixo, lixão municipal, poluição do ar, animais domésticos abandonados, pragas urbanas, e terrenos baldios abandonados.

Os dados coletados foram tratados e os resultados apresentados estatisticamente podem ser observados nos gráficos a seguir (Figuras 1 e 2).

Figura 1: Distribuição das médias obtidas para os problemas sociais (LIMA, 2008, p.129).

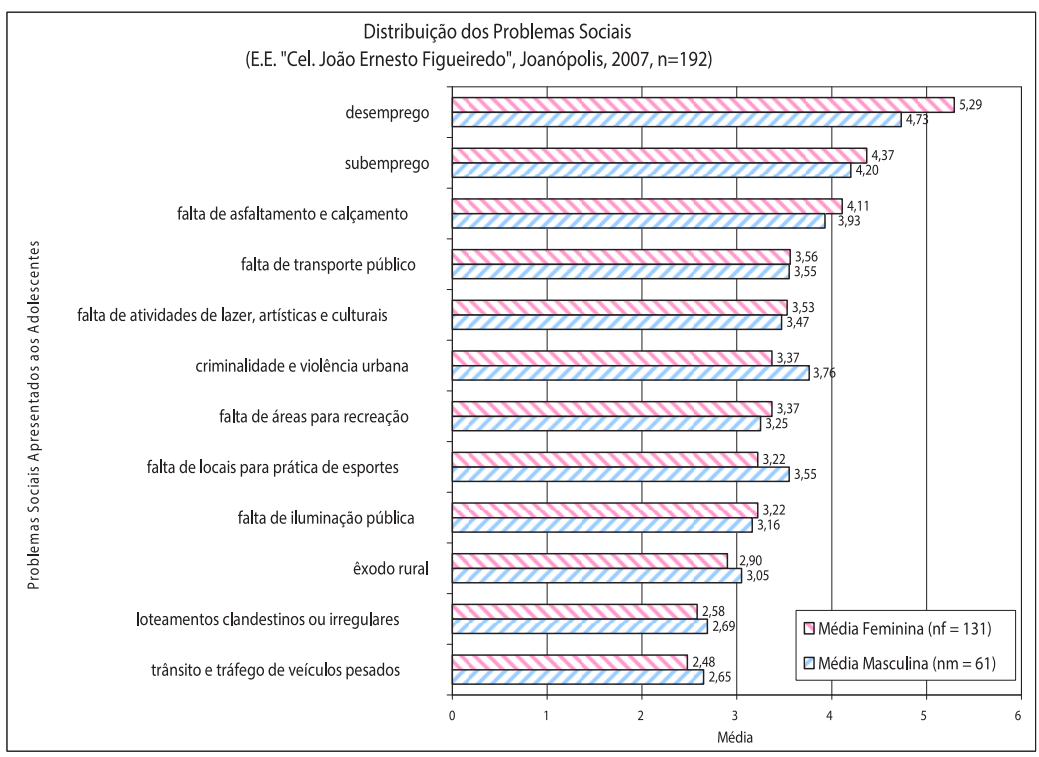

Nota: $\mathrm{n}=$ amostra, $\mathrm{nf}=$ amostra feminina, $\mathrm{nm}=$ amostra masculina 
Figura 2: Distribuição das médias obtidas para os problemas ambientais (LIMA, 2008, p.130).

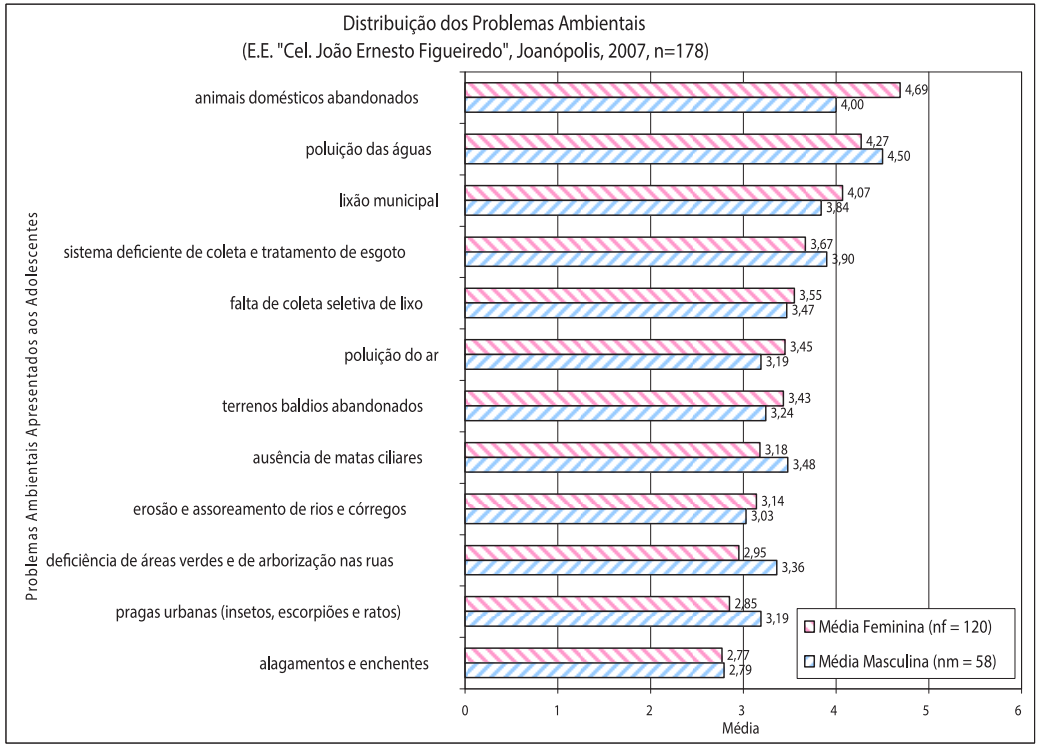

Nota: $\mathrm{n}=$ amostra $; \mathrm{nf}=$ amostra feminina $; \mathrm{nm}=$ amostra masculina

Os problemas cujo valor das médias ficaram entre 2 e 3 são menos significativos perceptivamente e, em geral, são de menor importância para os adolescentes participantes. Os que estão entre 3 e 4 foram aqueles cuja percepção e cognição começam e ter destaque, com média importância. Aqueles entre 4 e 5 já são problemas mais graves, com maior importância e de maior interesse para os adolescentes. Com média acima de 5 está um único problema mais significativo para os adolescentes, ímpar em sua importância, mais acentuadamente para as meninas: o desemprego. Não ter havido nenhum problema com média inferior a 2 demonstra que, dentre os problemas apresentados, nenhum deles foi insignificante, imperceptível ou desprezível para a percepção dos adolescentes.

Após a conclusão das análises dos dados, em continuidade, foi realizado um novo encontro com os adolescentes para uma apresentação geral dos resultados e para a realização de uma atividade para a elaboração conjunta de propostas e sugestões para a solução ou minimização de cada problema discutido. 
Essa última atividade resultou em uma coleção de comentários, propostas e sugestões elaboradas pelos adolescentes demonstrando que além de perceberem os problemas de seu entorno, os adolescentes também foram capazes de elaborar e apresentar ideias e sugestões interessantes para a resolução das questões sociais e ambientais abordadas e propor novas ações que permitiriam e incentivariam a continuidade de sua própria participação como atores sociais.

\section{Motivação: uma experiência em São José do Rio Preto (SP)}

Trata-se de uma experiência relatada em Catanho (2018) que foi realizada em 2017 na cidade de São José do Rio Preto, no interior de São Paulo, cujo município possui mais de 450.000 habitantes, distante cerca de $440 \mathrm{~km}$ a noroeste da capital estadual paulista.

O estudo foi realizado numa escola pública em um bairro de periferia da cidade. Os adolescentes envolvidos eram estudantes do $3^{\circ}$ ano do ensino médio e tinham entre 16 a 19 anos e a pesquisa foi realizada em forma de uma amostragem aleatória simples, contando com uma parcela dos alunos que estava presente no dia das entrevistas e que aceitaram participar voluntariamente. Os participantes responderam questionários específicos sobre motivação e, também, colaboraram com entrevistas individuais.

Posteriormente, os dados foram tratados estatisticamente e analisados comparativamente com a média das notas dos participantes, obtidas nos $1^{\circ}$ e $2^{\circ}$ bimestres daquele ano, em relação ao tipo de motivação de cada um, averiguado com as entrevistas (Tabela 2).

É importante salientar que a média numérica das notas não pode ser considerada como um dado objetivo, pois a avaliação numérica é um dado subjetivo convertido em menções numéricas. Porém, são números que servem como norteadores da compreensão de como os alunos podem aprender os conteúdos de interesse.

A Tabela 2 foi elaborada de modo a apresentar a correlação entre o nível de aprendizagem e a motivação dos adolescentes, estudantes do $3^{\circ}$ ano, em relação ao conteúdo programático do ensino médio e os dados obtidos na pesquisa mostraram que os adolescentes quando se designam mais motivados acabam se empenhando muito mais no processo de aprendizagem do que aqueles com menos motivação. 
Tabela 2: Correlação entre as médias das notas dos alunos e os tipos de motivação detectados (Catanho, 2018, p. 115, modificada).

\begin{tabular}{ccl}
\hline Aluno & Média & \multicolumn{1}{c}{ Tipo de motivação } \\
\hline 1 & 9,8 & Motivação Intrínseca e Regulação Identificada \\
\hline 2 & 9,6 & Motivação Intrínseca e Regulação Identificada \\
\hline 3 & 9,1 & Desmotivação, Regulação Introjetada e Regulação Identificada \\
\hline 4 & 6,9 & Regulação Externa e Regulação Identificada \\
\hline 5 & 7,5 & Desmotivação e Regulação Identificada \\
\hline 6 & 7,6 & Desmotivação, Regulação Externa e Regulação Identificada \\
\hline 7 & 6,0 & Desmotivação e Regulação Externa \\
\hline 8 & 5,8 & Desmotivação e Regulação Externa \\
\hline 9 & 6,1 & Desmotivação e Regulação Externa \\
\hline
\end{tabular}

Como resultado, analisando-se os dados apresentados na Tabela 2, verificou-se que os adolescentes participantes $n^{\circ} 1$ e 2 que se encontravam motivados intrinsecamente foram os que apresentaram as maiores médias bimestrais $(9,8 \mathrm{e}$ $9,6)$, o que indica haver uma relação direta entre a aprendizagem e a motivação. Inversamente, os alunos 7,8 e 9 foram designados com desmotivação e regulação externa e obtiveram as piores notas $(6,0 ; 5,7$ e 6,1$)$. Mas, a aprendizagem é um parâmetro extremamente complexo de se averiguar e de se compreender e isso é evidenciado com os alunos $n^{\circ} 3,4,5$ e 6 , pois suas notas variaram entre 9,1 até 7,6 e as motivações detectadas foram diversas.

\section{PERCEPÇÃO AMBIENTAL E MOTIVAÇÃO EM EDUCAÇÃO AMBIENTAL PARA ADOLESCENTES}

\section{Proposta de Nova Pesquisa Integradora}

Diante do exposto, pode-se inferir que, quando se pretende empregar a educação ambiental, tanto em sua fase de instrumentação técnica como nas práticas e ações, o proponente/pesquisador deve estudar, se apropriar de, e compreender quanto mais conhecimento for possível a respeito de percepção, cognição, motivação e aprendizagem dos participantes em relação aos assuntos relacionados às situações e aos problemas ambientais e sociais a respeito dos quais se pretende levá-los a participar e à ação, de modo a realizar a educação ambiental num nível 
mais profundo e com maior chance de êxito.

Partindo das experiências anteriores, com as pesquisas realizadas e apresentadas em Lima (2003, 2008) e em Catanho (2018), será desenvolvida uma pesquisa integrando estudos a respeito da percepção ambiental e da motivação de adolescentes para instrumentalizar ações em educação ambiental e que tenham os mesmos adolescentes como atores sociais.

Nessa pesquisa pretende-se realizar a Educação Ambiental Transformadora conforme apresentada em Loureiro (2004) como sendo uma vertente de educação ambiental que se apresenta como um elemento catalisador de transformação social com o incentivo a um maior exercício de cidadania dos agentes atuantes - sujeitos da pesquisa - ampliando-se o diálogo democrático.

Na prática, pretende-se aplicar essa vertente da educação ambiental como uma metodologia participativa desde as reflexões iniciais, depois na busca por soluções e também na realização de ações em torno de problemas ambientais e sociais a serem elencados e discutidos a partir do levantamento da percepção ambiental e da motivação dos próprios participantes.

Nessa proposta, a educação ambiental é entendida como parte indissociável do processo de pesquisa, integrando o conceitual teórico e os procedimentos metodológicos, indo ao encontro da metodologia da pesquisa-ação, conforme Andaloussi (2004) e Thiollent (2005), quanto uma proposta de ação coletiva e participativa para a construção de conhecimento com o objetivo de transformação social.

No contexto dessa proposta, a afinidade e o potencial de sinergia entre as práticas da educação ambiental transformadora e da metodologia de estudo da pesquisa-ação ficam evidentes quando são elencados os objetivos potenciais da pesquisa-ação:

a) A coleta de informação original acerca de situações ou de atores em movimento.

b) A concretização de conhecimentos teóricos, obtida de modo dialogado entre pesquisadores e membros representativos das situações ou problemas investigados.

c) A comparação das representações próprias aos vários interlocutores, com aspecto de cotejo entre o saber formal e 
saber informal acerca da resolução de diversas categorias de problemas.

d) A produção de guias ou de regras práticas para resolver os problemas e planejar as correspondentes ações.

e) Os ensinamentos positivos ou negativos quanto à conduta da ação e suas condições de êxito.

f) Possíveis generalizações estabelecidas a partir de várias pesquisas semelhantes e com o aprimoramento da experiência dos pesquisadores. (THIOLLENT, 2005, p. 45).

A partir desse conceitual teórico, inicialmente tendo como abrangência o município de Lages, SC, será aplicada uma pesquisa-piloto que buscará estudar e conhecer os estudantes de ensino médio de uma das unidades de Escola de Ensino Básico (EEB) da área urbana. A EEB onde será iniciada a pesquisa-piloto e será selecionada a partir de um levantamento de dados que inclui localização, disponibilidade de acesso e interesse local em participar do projeto e em estabelecer novas parcerias ou fortalecer parcerias existentes.

Para tanto, previamente, serão necessários estabelecer contatos com representantes da rede estadual de ensino e da unidade educacional de interesse e, em sequência, obter as devidas autorizações administrativas e familiares para a realização da pesquisa, visto tratarem-se de adolescentes que legalmente são dependentes de seus pais ou responsáveis legais.

Paralelamente serão realizados levantamentos de dados a respeito de problemas urbanos interessantes para a comunidade dentre os quais serão selecionados aqueles com maior destaque e com relevância para essa pesquisa.

Uma vez que a unidade escolar tenha sido escolhida e tenham sido obtidas as devidas autorizações, pretende-se realizar um levantamento da percepção ambiental quanto aos problemas sociais e ambientais selecionados e do nível de motivação dos adolescentes para atuar na solução dos problemas apresentados.

Esse estudo sempre estará pautado na abordagem qualitativa dos dados, valendo-se sempre que necessário de técnicas empregadas em pesquisas sociais, como entrevistas e observações, conforme apresentadas por Lüdke e André (1986) e tendo como exemplos os estudos realizados e apresentados em Lima $(2003,2008)$ e em Catanho (2018). 
Em Lima (2003) foram realizadas entrevistas estruturadas para o levantamento do conhecimento da população de São Carlos/SP a respeito de temas relacionados aos recursos hídricos. Essa experiência contribuirá para a elaboração de roteiros de entrevistas.

Na experiência relatada em Lima (2008) foram apresentados 24 problemas sociais e ambientais para o levantamento da percepção ambiental dos adolescentes de Joanópolis/SP participantes. Essa relação servirá de base para a construção de uma nova lista atualizada e adequada à realidade urbana de Lages, SC, município onde se pretende aplicar a nova pesquisa. Essa referência contribuirá para o estudo e a compreensão dos aspectos da percepção ambiental individual como elemento fundamental para a construção do conhecimento coletivo em relação aos problemas ambientais e sociais estudados na busca por soluções.

Em Catanho (2018) está apresentada uma discussão a respeito da fundamentação teórica a ser empregada no levantamento da motivação dos adolescentes na pesquisa proposta e também apresenta reflexões a respeito da importância do professor e de sua formação profissional na construção da motivação dos alunos em sala de aula e que servirá de base inicial para estabelecer relações entre a motivação e o cotidiano vivido pelos alunos sendo adolescentes em processo de desenvolvimento e de formação. Essa referência contribuirá com o estudo e a compreensão da motivação como elemento catalisador para a participação dos adolescentes nas ações de educação ambiental.

\section{Expectativa de Resultados e de Ações Futuras}

Após a realização da pesquisa-piloto, os dados obtidos servirão de subsídio para validar a perspectiva de ampliação e execução da pesquisa em outras escolares de Lages, SC, bem como em outros municípios, seguindo-se os mesmos critérios de adaptação empregados na transposição das experiências desenvolvidas em São Carlos e Joanópolis, SP(LIMA 2003, 2008), e São José do Rio Preto, SP(CATANHO, 2018), para outros municípios e localidades onde se pretenda desenvolver novas pesquisas-ações em educação ambiental com públicos adolescentes.

Cabe destacar que a proposta de replicação e transposição parcial das experiências anteriores é importante para cada nova situação de pesquisa, pois serve como base conceitual e experimental prática. Porém, como apontado em Andaloussi (2004) e em Thiollent (2005), no decorrer do desenvolvimento de uma pesquisa- 
ação é fundamental reconhecer que a cada nova experiência ou mesmo a cada nova etapa de uma mesma experiência, possivelmente são encontrados especificidades e contextos únicos que levam a descobertas, caminhos, conhecimentos, resultados e ações diferentes entre si e que formam um novo conteúdo de aprendizado que os pesquisadores levarão para uma próxima experiência.

Com a continuidade da pesquisa e a consolidação dos dados obtidos em Lages, SC, partindo das propostas em educação ambiental, apresentadas e desenvolvidas conjunta e ativamente pelos participantes, será elaborado e aplicado um conjunto de ações efetivas na perspectiva de realizar a educação ambiental transformadora para os adolescentes, público-alvo dessa pesquisa.

Essa nova etapa da pesquisa terá como objetivos a apresentação de propostas e a realização de ações para solução de problemas sociais e ambientais que terão sido trabalhados ao longo da realização da pesquisa, levando os atores sociais à ação.

Também, como objetivo secundário a ser alcançado, deverá haver o estabelecimento, ou o fortalecimento, de parcerias com setores de interesse, como a rede de EEB e outras unidades de ensino, públicas ou particulares, para a construção de agendas de ações em educação ambiental, havendo potencial para outras parcerias em educação e formação continuada de professores.

Ao mesmo tempo, a continuidade da construção do arcabouço teórico e a produção científica se darão com o desenvolvimento de um grupo de pesquisa envolvendo professores de ensino médio, professores de ensino superior e alunos de graduação interessados nos temas abordados, e com a realização de eventos científicos e a publicação continuada de novos artigos com os resultados obtidos com finalização das etapas da pesquisa inicial e com a realização de outras pesquisas a serem desenvolvidas futuramente.

\section{CONSIDERAÇÕES FINAIS}

Como a educação ambiental transformadora está fundamentada, basicamente, na mudança de valores e de atitude, visando o envolvimento e a participação, individual ou em grupo, na solução de problemas ambientais e sociais, é necessário entender como se dá a apropriação das informações de interesse apresentadas para os indivíduos os quais se pretende sensibilizar, incentivar e motivar para agir em prol de um objetivo comum, de modo a direcionar da melhor 
forma possível os recursos disponíveis para potencializar o alcance e a eficiência da ação.

Para tanto, é primordial compreender que é através do processo de percepção e cognição que se inicia a conscientização e a motivação. Ou seja, é necessário estudar e conhecer a percepção ambiental e a motivação dos grupos de interesse, dos atores sociais específicos, que se pretende envolver nas ações de educação ambiental para se alcançar melhores resultados.

Os adolescentes, de forma geral, compõem um grupo específico interessante para as ações em educação ambiental. Os estudos a respeito da percepção ambiental e da motivação dos adolescentes quanto aos problemas ambientais e sociais são uma maneira de conhecer mais a respeito dos adolescentes e, ao mesmo tempo, uma oportunidade de incentivá-los à participação ou, ao menos possibilitar, à manifestação de suas opiniões e ideias.

A proposta de pesquisa esboçada é ambiciosa, mas, também, plenamente exequível, desde que haja empenho e apoio, humano e logístico, para a realização das etapas componentes. A partir da realização de uma pesquisa-piloto embasada, planejada e executada conforme as experiências anteriores destacadas espera-se alcançar excelentes resultados e o estabelecimento de uma base sólida para a criação e a continuidade de parcerias em prol da ciência, do ambiente e da sociedade.

\section{REFERÊNCIAS}

BECKER, Daniel. O que é adolescência. 13. ed. São Paulo: Brasiliense, 1994. (Primeiros Passos, 159).

BERGAMINI, Cecília Whitaker. Motivação. São Paulo: Atlas, 1986.

BRASIL. Lei n⿳ 8.069, de 13 de julho de 1990. Dispõe sobre o Estatuto da Criança e do Adolescente e dá outras providências. Diário Oficial da União, Brasília, DF, 16 de julho de 1990. Disponível em: https://www.planalto.gov.br/ ccivil_03/leis/18069.htm. Acesso em: 08 de jan. 2020.

BZUNECK, José Aloyseo. A motivação do aluno: aspectos introdutórios. In: BORUCHOVITCH, E.; BZUNECK, J. A. (Orgs.). A motivação do aluno: contribuições da psicologia contemporânea. 4. ed. Petrópolis: Vozes, 2009. cap. 1, 
p. 9-36.

CATANHO, Marciana. Relações entre motivação e aprendizagem no ensino de Química. Orientação: Jackson Gois. 2018. 149 f. Dissertação (Mestrado em Ensino em Ciências) - Programa de Pós-Graduação em Ensino e Processos Formativos, Instituto de Biociências, Letras e Ciências Exatas, Universidade Estadual Paulista “Júlio de Mesquita Filho", UNESP, São José do Rio Preto, SP.

CHARBONNEAU. Paul-Eugène. Adolescência e liberdade. São Paulo: EPU, 1980.

DEL RIO, Vicente. Cidade da mente, cidade real: percepção ambiental e revitalização na área portuária do RJ. In: DEL RIO, Vicente; OLIVEIRA, Lívia de. Percepção ambiental: a experiência brasileira. 2. ed. São Paulo: Studio Nobel; São Carlos: EdUFSCar, 1999. p. 3-22.

DEL RIO, Vicente; OLIVEIRA, Lívia de. Percepção ambiental: a experiência brasileira. 2. ed. São Paulo: Studio Nobel; São Carlos: EdUFSCar, 1999.

EL ANDALOUSSI, Khalid. Pesquisas-ações: ciências, desenvolvimento, democracia. São Carlos: EdUFSCar, 2004.

FORGUS, Ronald Henry. Percepção: o processo básico do desenvolvimento cognitivo. São Paulo: EPU, 1981. Reimpressão.

GROSSMAN, Eloísa. A adolescência através dos tempos. Adolescencia Latinoamericana, Porto Alegre. v. 1, n. 2, p. 68-74, 1998.

JACOBI, Pedro. Meio ambiente e sustentabilidade: alguns elementos para a reflexão. In: CAVALCANTI, Clóvis (Org.). Meio ambiente, desenvolvimento sustentável e políticas públicas. 4. ed. São Paulo: Cortez; Recife: Fundação Joaquim Nabuco, 2002.p. 384-390.

. Educação ambiental, cidadania e sustentabilidade. Cadernos de Pesquisa,São Paulo, n. 118, p. 189-205, mar. 2003.

LIMA, Roberto Teixeira de. Percepção ambiental e participação pública na 
gestão dos recursos hídricos: perfil dos moradores da cidade de São Carlos, SP (bacia hidrográfica do rio do Monjolinho). Orientação: Haydée Torres de Oliveira. 2003. 94 f. Dissertação (Mestrado em Ciências da Engenharia Ambiental) Programa de Pós-Graduação em Ciências da Engenharia Ambiental, Escola de Engenharia de São Carlos, Universidade de São Paulo, EESC/USP, São Carlos, SP.

. Percepção e cognição de problemas urbanos por adolescentes de Joanópolis (SP). Orientação: Lívia de Oliveira. 2008. 179 f. Tese (Doutorado em Geografia) - Programa de Pós-Graduação em Geografia, Instituto de Geociências e Ciências Exatas, Universidade Estadual Paulista "Júlio de Mesquita Filho", UNESP, Rio Claro, SP.

LOUREIRO, Carlos Frederico Bernardo. Educação ambiental transformadora. In: LAYRARGUES, Philippe Pomier. Identidades da educação ambiental brasileira. Brasília: Ministério do Meio Ambiente, 2004. p. 65-84.

LÜDKE, Menga; ANDRÉ, Marli E. D. A. Pesquisa em educação: abordagens qualitativas. São Paulo: EPU, 1986.

MORIN, Edgar. Os sete saberes necessários à educação do futuro. 9. ed. São Paulo: Cortez; Brasília: UNESCO, 2004.

OLIVEIRA, Lívia de. Contribuição dos estudos cognitivos à percepção geográfica. Geografia, Rio Claro, SP, v. 2, n. 3, p. 61-72, 1977.

REEVE, Johnmarshall. Motivação e emoção. 4. ed. Rio de Janeiro: LTC, 2019. Reimpressão.

REIGOTA, Marcos. Meio ambiente e representação social. 4. ed. São Paulo: Cortez, 2001.

. O que é educação ambiental. 1. ed. São Paulo: Brasiliense, 2006. Reimpressão.

SANTOS, José Eduardo dos; JESUS, Terezinha P.; HENKE-OLIVEIRA, Carlos; 
BALLESTER, Maria V. Ramos. Caracterização perceptiva da Estação Ecológica de Jataí (Luiz Antonio, SP) por diferentes grupos socioculturais de interação. In: SEMINÁRIO REGIONAL DE ECOLOGIA, 7., 1996, São Carlos, SP. Anais... São Carlos, SP: UFSCar, 1996. p. 309-353.

THIOLLENT, Michel. Metodologia da pesquisa-ação. 14. ed. São Paulo: Cortez, 2005.

TUAN, Yi-Fu. Topofilia: um estudo da percepção, atitudes e valores do meio ambiente. São Paulo: DIFEL, 1980.

Recebido em: 02/08/2021 Aceito em: 19/11/2021 